\title{
A Review on performance of coir fiber reinforced sand
}

\author{
R.Sridhar ${ }^{\# 1}$ \\ ${ }^{\# i}$ Research Scholor in VTU,Belgaum. \\ Associate Professor, Department of Civil Engg.,Nagarjuna college of Engg. \& Technology,Bangalore,India \\ ${ }^{1}$ sridharr@ncetmail.com
}

\begin{abstract}
Reinforced earth is a composite material, a combination of soil and reinforcement duly placed to bear the tensile stresses developed and also to improve the resistance of soil in the direction of maximum stress. The majority of currently published literature about randomly oriented fiber reinforcement deals with the reinforcement of cohesion less or granular soils.. Availability, economical benefits, easy to work and rapid to perform; and feasibility of using in all weather conditions are the general advantages of short fiber composite soils. The technical benefits of using fibers in soil reinforcement include: preventing the formation of the tensile cracks, increasing hydraulic conductivity and liquefaction strength, reducing the thermal conductivity and weight of building materials, restraining the swelling tendency of expansive soils; and decreasing the soil brittleness. It can be concluded that the increase in strength and stiffness was considered to be a function of Fiber characteristics like aspect ratio, skin friction, weight fraction modulus of elasticity, shape, particle size and gradation of sand and confining stress condition.
\end{abstract}

Keyword- Coir fiber, Coir geotextile, Biodegradable, Shear strength, Bearing capacity and Shear plane

\section{INTRODUCTION}

Soil mass is normally a discrete system which consists of soil grains. It cannot tolerate tensile stresses and this is mainly true in the case of cohesion less soil like sand. Such soils cannot be stable on steep slopes and relatively large strains are caused when external loads are imposed on them. Reinforced earth is a composite material, a combination of soil and reinforcement duly placed to bear the tensile stresses developed and also to improve the resistance of soil in the direction of maximum stress. The existence of reinforcement alters the stress field giving a restraint mainly in the form of friction or adhesion so that less strain induced and tension is avoided. Fiber reinforcement is one of the novel emerging soil reinforcement techniques. Absence of weak plane is foremost advantage of fiber reinforcement. It is like the reinforcement provided by the plant of roots. Randomly distributed fibers provide interlocking and friction resistance to resist the movement of soil particles, which considerably increase the load carrying capacity. Now a days fiber reinforcement is used in the embankment, slope stabilization, pavement application. For efficient application of fiber reinforcement, proper understanding of effect of different parameters like fiber parameters and soil parameters on the behaviour of fiber reinforced soil is required.

In ancient times, fiber was used for reinforcing soils. Early civilizations added straws and plant roots to soil bricks and cob wall to improve their properties although their mechanisms were not fully understood. However, modern geotechnical engineering has focused on the use of planar reinforcement. The reinforcing of soil with discrete fibers is still a comparatively new skill in geotechnical Engineering. The concept of fiber-reinforcement in geotechnical projects originally involved the use of plant roots as reinforcement. Most researchers reported that plant roots increased the shear strength of the soil and the stability of natural slopes. With development of polymeric fiber since the late 1980s, triaxial compression tests, unconfined compression tests and direct shear tests have been conducted to study the effect of synthetic fiber-reinforcement on shear strength. Additionally, fiber-reinforcement previously was used to improve the road structure. Fiber reinforced subgrade had noteworthy influence on unconfined compression strength of silty sand. Previous research has shown that fiberreinforcement could increase the peak shear strength and limited post peak reductions in shear resistance and decreased the stiffness of the soil. Most of the experimental studies were conducted using granular soils. The mechanisms of fiber-reinforcement on dry sand reinforced with different types of fiber by using direct shear tests have been studied. Fibers were placed at different specific orientations with respect to the shear plane. The fiber content, orientation of fibers, and modulus of fibers were found to influence the contribution of fibers to the shear strength development. The behavior of sand reinforced with discrete randomly oriented inclusions among other factors on particle shape and size of the sand has been investigated. The effect of fiberreinforcement was found to be more significant in fine sand with sub rounded particles than in medium grained sand with sub angular particles. 
The model proposed by $\mathrm{Wu}$ only considers an inclusion oriented perpendicularly to the shear surface. This model tacitly assumes full mobilization of the tensile strength of the inclusions (or roots). Waldron's model meanwhile is based on only partial mobilization of inclusion tensile strength depending upon the amount of inclusion elongation during shear. Neither model places any constraint on the distribution or location of the reinforcing inclusions.

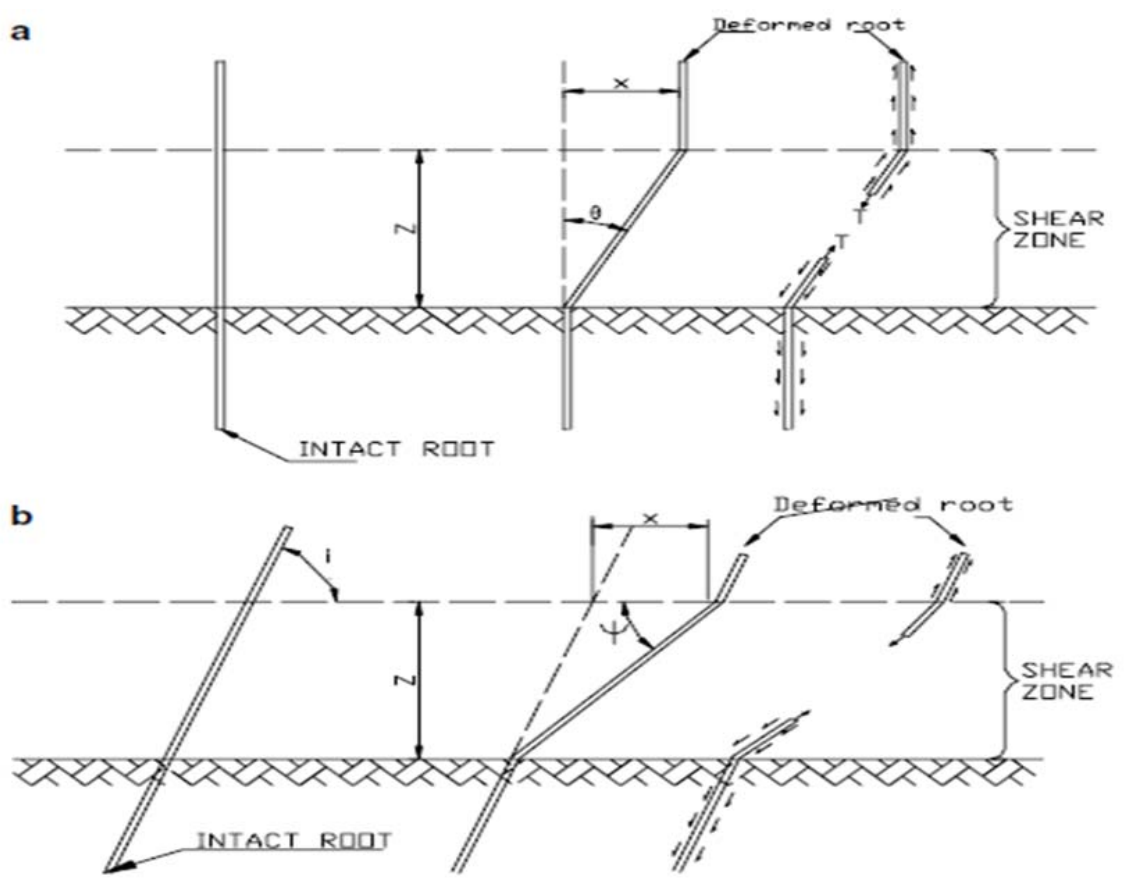

Fig. 1. Fiber reinforcement model: (a) perpendicular orientation to shear plane; (b) fiber oriented at angle (i) to shear plane.

The model is shown in Fig. 1. Reinforcements may be oriented initially perpendicular to the shear plane, Fig. 1(a) or at some arbitrary angle, Fig. 1(b). Shearing causes the reinforcement to distort as shown in Fig. 1, there by mobilizing tensile resistance in the inclusion. The tensile force in the reinforcement can be divided into a component normal and tangential to the shear plane. The normal component increases the confining stress on the failure plane thereby mobilizing extra shear resistance in the sand while the tangential component directly resists shear. If many inclusions are present their cross section areas are computed and the total reinforcement concentration is expressed in terms of a reinforcement area ratio (AR/A), or as a ratio of reinforcement total shear cross-sectional area to total area.

\subsection{Advantages of fiber-reinforced soil}

Randomly distributed fiber-reinforced soil have many advantages to be considered such as Increase in shear strength with maintenance of strength isotropy, Beneficial for all type of soils (i.e. sand, silt and clay), Reduced Post peak strength loss, Increased ductility, Increased seismic performance, No catastrophic failure, Great capacity to use natural or waste material such as coir fibers and recycled waste plastic strips, Provide erosion control and facilitate vegetation development, Reduce shrinkage and swell pressures of expansive soil, No noticeable change in permeability, Unlike lime, cement, and other chemical stabilization methods, the construction using fiber-reinforcement is not greatly affected by weather conditions, Fiber-reinforcement has been helpful in discarding the shallow failure on the slope face and thus reducing the cost of maintenance.

The strength and properties of randomly distributed fiber-reinforced soil was affected by the factors such as type of soil , type of Fiber: monofilament or fibrillated ,fiber content: expressed in \% with respect to weight of soil, density of fiber, fiber length , aspect ratio and fiber-soil surface friction.

Natural and artificial fibers are the two types of fibers. Both the types are used for civil engineering purposes. Soft silty or clayey soils can be enhanced with reinforcement in the form of randomly distributed fibers of natural and synthetic types. Use of natural fibers such as cotton, bamboo, jute, coir, etc. as soil reinforcing materials has been prevalent for a long time. The concern in natural fiber reinforcement in soil has increased 
rapidly due to the growing environmental consciousness and understanding of the need for sustainable development to replace man-made artificial fibers. The advantages of natural fibers include low density, low price, easy availability, and low abrasive wear of processing machinery. Further, natural fibres are biodegradable, recyclable and carbon dioxide neutral and their energy can be recovered in an environmentally acceptable way. The main advantage of these materials is that they are locally available and cost effective. Natural fibers are biodegradable and therefore eco-friendly. Synthetic fibers such as polypropylene, polyester, polyethylene and glass fibers have also been used as reinforcing materials. There are environmental problems in the use of artificial fibers. The random inclusion of various types of fibers is a process in which the fibers act to interlock soil particles and aggregates in a unitary coherent matrix. The fiber-reinforced soil behaves as a composite material. When loaded, the fibers mobilize tensile resistance, which in turn provides greater strength to the soil. Natural or synthetic fibers In been used in the construction of pavement layers, road and railway embankments, and retaining walls as well as in the protection of slopes. The primary purpose of reinforcing a soil mass is to improve its stability by increasing its bearing capacity, and by reducing settlement and lateral deformation. Among the natural fibers, Coir is produced in large quantities in South Asian countries. The coir fibers have been found to have good strength characteristics and resistance to bio-degradation over a long period of time. Coir fiber is extracted from green coconut husk after retting in flowing, circulating or changed water (lagoon-river) for a phase of minimum 3 months. Long retting will remove much acid and pectin, which can cause oxidation and shortens the life of fiber. India is the major manufacturer (66\% of total world production) of coir fiber from the husk of coconut fruit. The haphazard destruction of potentially useful materials owes much to the lack of alternate end uses of coir fibers.

Coir is a natural biodegradable material that is abundantly available in India. Due to high lignin content (about $46 \%$ ) it is stronger than other natural materials such as jute or cotton. Coir fibers are extracted from the husks surrounding the coconut. Coir has better mechanical properties, such as tensile strength. Coir has a longer life compared to other natural fibers that degrade much faster, it is possible to use these fibers in rural roads and ground improvement. Coir uses in various geotechnical engineering applications are ecologically safe. Coir geotextiles have been used in various slope stabilisation and soil erosion control projects. Addition of coir (1$2 \%$ ) as randomly reinforcing material increases both strength and stiffness of clayey soil. Coir fiber mixed soil can be used to increase the piping resistance and reduce seepage velocity. The shear strength of marine clay increases considerably by the inclusion of the coir fibers by about four times. The inclusion of coir fiber enhanced the California Bearing Ratio strength of the clayey soil significantly. For low cost embankment/rural road constructions, randomly distributed discrete natural fiber reinforced soils may result in significant cost advantages. Coir fiber enhanced the liquefaction resistance of loose Saloni sand significantly. Addition of coir to clayey soil improves UCC and California Bearing Ratio. Coir fiber is strong fiber among all natural fibers, however it needs supplementary treatment in order to prolong its service life as reinforcing material to soil.

\section{Material}

\subsection{Physical properties of coir fibre}

Length in inches 6-8

Breaking Elongation $\% 30 \%$
Density $(\mathrm{g} / \mathrm{cc}) 1.40$

Diameter in $\mathrm{mm} 0.1$ to 0.5
Tenacity $(\mathrm{g} / \mathrm{Tex}) 10.0$

Rigidity of Modulus 1.8924 dyne $/ \mathrm{cm} 2$

\subsection{Chemical properties of coir fibre:}

Lignin $45.84 \% \quad$ Cellulose $43.44 \%$ Hemi-Cellulose $0.25 \% \quad$ Pectin's and related Compound $3.0 \%$ Water soluble $5.25 \%$ Ash 2.22\%.

\section{INVESTIGATION}

The conception of soil reinforcement was first developed by Vidal (1969). He established that the introduction of reinforcement elements in a soil mass increases the shear resistance of the soil matrix. The main purpose of reinforcing soil mass is to improve its stability, increase its bearing capacity and reduce settlements and lateral deformation (Housman- 1990, Prabaker \& Sridhar- 2002). The investigations point towards the strength properties of fiber reinforced soils are the function of fiber content, fiber - surface friction along the soil mass and fiber strength characterises. (Hoare- 1979, Gray and Ohashi- 1983,Maher- 1988, Ranjan et al.- 1996, Nataraj \& Mcmanis-1997,Kaniraj \& Havanagi- 2001,Yetimoglu \& Salbas-2003, Praveenkumar \& Swami 2008, Ameta- 2009). McGown, Andrews \& Hytiris(1985) Drained triaxial test and model footing tests were done. Result showed that mesh increased the deviator stress developed at all strains, even at very small strains and the peak stresses in the sand-mesh mixture occurred at slightly higher axial strains than for the sand alone. 
Very huge improvements were obtained at all strain levels which were similar to triaxial tests in terms of both strength and deformation characteristics. Recoverable settlement plot shows that where a layer of sand -mesh mixture was present, almost $20 \%$ of the imposed vertical settlement was recovered, which was 4 times that for the soil alone.

The majority of currently published literature about randomly oriented fiber reinforcement deals with the reinforcement of cohesion less or granular soils. Only limited information has been reported on the use of randomly distributed discrete fibers for clayey soils in the literature. Most of the above studies on fiber reinforced soil were conducted on small scale such as C.B.R., unconfined compression, direct shear and triaxial tests etc. Very few studies were reported on influence of fibers on soil under model footing test. Thus an experimental programme using model footing test on larger scale has been undertaken on fiber reinforced clayey soil.

Direct shear tests were run on dry sand reinforced with different types of fibers. Both natural and synthetic fibers plus metal wires were tested. Experimental behavior was compared by Donald H. Gray, A. M. and Harukazu Ohashi with theoretical predictions based on a force equilibrium model of a fiber reinforced sand. Test results showed that fiber reinforcement increased the peak shear strength and limited post peak reductions in shear resistance. The fiber reinforcement model precisely predicted the influence of various sand-fiber parameters through shear strength increases that were: (1) Directly proportional to concentration or area ratio of fibers; (2) greatest for initial fiber orientations of $60^{\circ}$ with respect to the shear surface; and (3) approximately the same for a reinforced sand tested in a loose and dense state, respectively. The findings of this study are relevant to such diverse problems as the contribution of roof reinforcement to the stability of sandy, coarse textured soils in granitic slopes, dune and beach stabilization by pioneer plants, tillage in root permeated soils, and soil stabilization with low modulus, woven fabrics.

Geotechnical engineers often encounters problems in designing foundations of structures on highly compressible clayey soil due to its poor bearing capacity, low shearing strength, etc. Soil reinforcement is an effective and reliable technique for improving strength and stability of soils. Maheshwari, K.V. Desai, A.K. Solanki, C.H. investigated the influence of randomly distributed fibers on highly compressible clayey soil, series of laboratory model footing tests were conducted. The dosages of polyester fibers having $12 \mathrm{~mm}$ in size were taken as $0.25 \%, 0.50 \%$ and $1.00 \%$. The results of load settlement curve of different sizes of square footing on unreinforced soil and soil reinforced with various amount and depths of fiber reinforced soil were recorded. The bearing capacity is also calculated in term of bearing capacity ratio. The results indicate that reinforcement of highly compressible clayey soil with randomly distributed fibers caused an increase in the ultimate bearing capacity and decrease in settlement at the ultimate load.

Wasti Y., Butun M.D. conducted a series of laboratory model tests on a strip footing supported by sand reinforced by randomly distributed polypropylene fiber and mesh elements was conducted in order to compare the results with those obtained from unreinforced sand and with each other. For conducting the model tests, uniform sand was compacted in the test box at its optimum moisture content and maximum dry density. Three types of reinforcement, two sizes of mesh elements having the same opening size and one size of fiber element cut from the meshes, were used in varying amounts in the tests. Results indicated that reinforcement of sand by randomly distributed inclusions caused an increase in the ultimate bearing capacity values and the settlement at the ultimate load in general. The effectiveness of discrete reinforcing elements was observed to depend on the quantity as well as the shape of the inclusions. The larger mesh size was found to be superior to other inclusions in view of the ultimate bearing capacity values. For the mesh elements there appears to be an optimum inclusion ratio, whereas fibers exhibited a linearly increasing trend on the basis of an increase in ultimate bearing capacity for the range of reinforcement amounts employed.

Fiber reinforcement can help to improve soil strength, stabilize near-surface soil layers, and diminishes the risk of soil liquefaction. Evaluation of the strength of fiber-reinforced soils needs a proper failure criterion. The study by Zhiwei Gao and Jidong Zhao presents a three-dimensional failure criterion for fiber-reinforced sand. By assuming that the total strength of the composite is a combination of the shear resistance of the host soil and the reinforcement of fibers, a general anisotropic failure criterion is proposed with special emphasis on the effect of isotropically/anisotropically distributed fibers. An anisotropic variable, defined by the joint invariant of the deviatory stress tensor and a deviatory fiber distribution tensor, is introduced in the criterion to compute the fiber orientation with respect to the strain rate/stress direction at failure. With further consideration of the fiber concentration and other factors such as aspect ratio, the proposed criterion is applied to predicting the failure of fiber-reinforced sand in conventional triaxial compression/extension tests for both isotropically and anisotropically distributed fiber cases. The predictions are in good agreement with the test results available in 
the literature. The practical significance of using this criterion for such problems as inclined slope stabilization is briefly discussed.

A series of triaxial compression tests were carried out by Gopal Ranjan,l R. M. Vasan and H. D. Charan on cohesionless soils reinforced with discrete, randomly distributed fibers, both synthetic and natural, to study the influence of fiber characteristics (i.e., weight fraction, aspect ratio, and surface friction) soil characteristics and its density, and confining stress on shear strength of reinforced soils. A regression analysis of test results has been carried out to develop a mathematical model to bring out the effect of these factors on the shear strength of reinforced soil. The model estimates the strength of soils reinforced with any type of fiber and under given stress environment. The model predictions agree reasonably well with the experiment results and the results published in the literature. The test results show that the failure envelopes of soil-fiber composites have a curvilinear failure envelope, with a transition occurring at a certain confining stress, termed as "critical confining stress," below which the fibers tend to slip. The amount of the critical confining stress is affected by the fiber aspect ratio. Fiber inclusion increases significantly the shear strength of soil. The increase in strength is task of fiber weight fraction, aspect ratio and soil grain size.

Short fibers have been tried in the past few years as a soil-improvement admixture (reinforcement), yet no failure criteria for fiber-reinforced soils, consistent with numerical methods for solving boundary-value problems, are available. An attempt at deriving the limit condition for a fiber-reinforced granular soil is presented by Radoslaw L. Michalowski, and Aigen Zhao. An energy-based homogenization scheme is used to arrive at the macroscopic failure stress of the fibrous granular composite. A piecewise closed-form failure criterion is derived. The internal friction angle is used to quantify the strength of the granular matrix and the fibers are characterized by volumetric concentration, aspect ratio, yield point, and the fiber-soil interface friction angle. Laboratory tests on specimens with low fiber content indicate a good agreement of the model predictions with the actual test results.

The properties of the fibre-reinforced sand are anisotropic because of the distribution of orientation of the fibres, which is characterised by a preferred bedding plane. The development of an anisotropic yield condition for fiber reinforced sand is presented by R. L. Michalowski. Application of the kinematic approach of limit analysis to anisotropic frictional materials is demonstrated. An interesting implication of anisotropy is a lack of uniqueness in the internal friction angle along a shear surface with given orientation. The anisotropic internal friction angle was found to be a function of the major principal strain rate direction, and not just a function of the orientation of the shear surface. While the inclination of principal strain rate directions can be inferred from the kinematics of the mechanism for a given boundary value problem, the internal friction angle cannot be determined a priori as a unique function of orientation in space. They illustrated the use of the kinematic approach for anisotropic frictional materials: retaining wall loading, and the bearing capacity of a footing.

Several models were recommended to assess the improvement brought by fibers to the shear strength of soils. Salah Sadek, Shadi S. Najjar,and Fadi Freiha investigated the effectiveness of current models in predicting the improvement in shear strength of fiber-reinforced sand. An extensive direct shear testing program was implemented using coarse and fine sands tested with three types of fibers. Results show the existence of a fibergrain scale effect which is not catered for in current prediction models. A comparison between measured and predicted shear strengths indicates that the energy dissipation model is effective in predicting the shear strength of fiber-reinforced specimens in reference to the tests conducted in this study. On the other hand, the effectiveness of the predictions of the discrete model is affected by the parameters of the model, which may depend on the test setup and the system used for mixing the fibers.

Laboratory triaxial compression tests are performed by Mohamad H. Maher and Donald H. Gray to find out the static stress-strain response of sands reinforced with discrete, randomly distributed fibers, and observed the influence of various fiber properties, soil properties, and test variables on soil behaviour. In addition to the experimental program, a model is developed, based on a statistical theory of strength for composites, to predict the fiber contribution to strength under static loads. Randomly distributed fiber inclusions significantly increase the ultimate strength and stiffness of sands. The increase in strength and stiffness is a function of gradation and particle size and shape of sand and fiber properties (i.e., weight fraction, aspect ratio and modulus). The sandfiber composites have either a curved linear or a bilinear failure envelope, with the break occurring at a threshold confining stress called the "critical confining stress." The magnitude of the critical confining stress decreases with an increase in sand gradation, particle angularity, and fiber aspect ratio, and increases with an increase in fiber modulus. The critical confining stress is insensitive to changes in sand particle size and fiber content. Predicted strength increases from fiber reinforcement using a theoretical model based on a statistical theory of strength for composites agree reasonably well with measured values. 
After a number of investigation made by Gu,H.(2009) Tran, N.-H.,.Girisha,C et al.(2012), It was further concluded that alkali treatment of the natural fibres is required to develop moderate mechanical properties as well as better adhesion between fibres and matrix. The coir fiber is biodegradable, so to modify its life, several treatment has been tried by the Investigators.

The characterisation and utilisation of natural coconut fibre composites was studied by Wei,W. and Gu ,H.(2009). Two thousand randomly taken fibres were analysed for their characteristics. The average length of the fibres, the average weight range of the fibres was investigated and composites were manufactured .The tensile strength of the composites was investigated.

The tensile behaviour of the coir fibre and related composites after $\mathrm{NaOH}$ treatment were evaluated by $\mathrm{Gu}, \mathrm{H}(2009)$. Coir fibres were treated with varying concentrations of $\mathrm{NaOH}(2 \%-10 \%)$ and the tensile strength of the alkali treated fibre was measured .It was found that the fibres showed a decreasing trend of fibre tensile strength with increasing $\mathrm{NaOH}$ density. Study further suggested that in lower concentrations of $\mathrm{NaOH}$, fibre detoriation was comparatively less and it was outweighed by the improvement in strength provided by the adhesion between fibre and the matrix.

The influence of fibre treatment on the performance of coir polyster composites has also been studied by Rout,J et al.(2001). Study recommended that mechanical properties of the composites like tensile, flexural, impact strength increase as a result of surface modification. Bleached coir polyster composite showed better flexural strength while alkali treated coir polyester composite showed significant improvement in tensile strength. Both hybrid and coir polyester composites showed significant reduction in water absorption due to surface modification of coir fibre

Water Absorption (WA) tests conducted Ramesh H.N et al.(2010) on coir fibers .The weight of the uncoated coir before immersing in water is $10 \mathrm{~g}$ and after immersing in water, the weight of the uncoated coir fiber is 63.7g for 1day immersion in water. The Water Absorption Capacity (WAC) of uncoated coir fiber is $537 \%$. When coir coated with kerosene by $60 \%$ weight of coir, WAC is reduced to $364 \%$. WAC of kerosene coated coir fiber reduced by $32 \%$ as that of uncoated coir. WA tests are also conducted on kerosene coated coir fibers mellowed for period of 1 day, 2 day and 3 day. Further, WAC of kerosene coated coir fiber is reduced to 298\%, $223 \%$, and $210 \%$ with mellowing time of 1 day, 2 day, and 3 day respectively. From this it can be said that 2 day mellowing of kerosene coated coir is sufficient. It is noticed that 2 day mellowed kerosene coated coir fiber reduces the WAC from $537 \%$ to $223 \%$. WAC of 2 day mellowed kerosene coated coir fiber reduced by $58 \%$ as that of uncoated coir. Hence the WA nature of the kerosene coated coir fiber is decreased, it may be said that the longevity (durability) of kerosene coated coir fiber is increased against Biological degradation. From WA test kerosene coated fibers are used for further study because of low WAC.

The papers mentioned above have generally shown that strength and stiffness of the composite soil is improved by fiber reinforcement. It can be concluded that the increase in strength and stiffness was considered to be a function of Fiber characteristics like aspect ratio, skin friction, weight fraction modulus of elasticity, shape, particle size and gradation of sand and confining stress condition.

\section{IV.CONCLUSION}

The inclusion of fibers causes an increase in peak shear strength and reduction in the loss of post-peak stress. Thus, residual strength of fiber-reinforced soil is higher as compared to unreinforced soil.

Shear strength increases roughly linearly with increase in amount of fiber, then approaches an asymptotic upper limit governed essentially by confining stress and fiber aspect ratio.

Direct shear tests, unconfined compression tests and conventional triaxial compression tests have confirmed that shear strength is increased and post-peak strength loss is reduced when discrete fibers are mixed with the soil. In other words, discrete, randomly distributed fiber inclusions appreciably increase the peak shear strength, lessen the post peak strength loss, increase the axial strain to failure and in some cases change the stress-strain behaviour from strain softening to strain hardening. Fiber inclusions also hinder the compaction process, causing a reduction in the maximum dry density of reinforced specimens with increasing fiber content. The strength losses associated with in-service saturation are significantly reduced with fiber reinforcement. Altogether, it is necessary to mention that research on the use of fibers with cohesive soils has been more limited. The main reason is that while chemical binders improve the stability of the soil, at the same time, they decrease the ductile behaviour of the soil. Fibers, in this way, help to reduce the brittleness factor of the composite soil.

Availability, economical benefits, easy to work and rapid to perform; and feasibility of using in all weather conditions are the general advantages of short fiber composite soils. The technical benefits of using fibers in soil reinforcement include: preventing the formation of the tensile cracks, increasing hydraulic conductivity and liquefaction strength, reducing the thermal conductivity and weight of building materials, restraining the swelling tendency of expansive soils; and decreasing the soil brittleness. As well, a comprehensive literature 
review shows that using natural and/or synthetic fibers in geotechnical engineering is feasible in six fields including pavement layers (road construction), retaining walls, earthquake engineering, railway embankments, protection of slopes; and soil-foundation engineering. At final, it is emphasized that short fiber composite soil is still a relatively new technique in geotechnical projects as a mimics of the past.

\section{REFERENCES}

[1] Ling I, Leshchinsky D, Tatsuoka F. Reinforced soil engineering: advances in research and practice. Marcel Dekker Inc.; 2003.

[2] Jones M. Mechanics of composite materials. 2nd ed. Taylor and Francis; 1999.

[3] Kazemian S, Huat K, Prasad A, Barghchi M. A review of stabilization of soft soils by injection of chemical grouting. Aust J Basic Appl Sci 2010;4:5862-8.

[4] Abtahi M, Allaie H, Hejazi M. An investigative study on chemical soil stabilization. In: 8th Int cong civ eng, Shiraz, Iran; 2009.

[5] Abtahi M, Sheikhzadeh M, Hejazi M, Hassani Y. Compressive behavior of composite soils reinforced with recycled waste tire cords and poly propylene fibers. In: 1st Int and 7th nat conf text eng, Rasht, Iran; 2009.

[6] Ola A. Stabilization of lateritic soils by extensible fiber reinforcement. Eng Geol 1989;26:125-408.

[7] Prabakar J, Dendorkar N, Morchhale K. Influence of fly ash on strength behavior of typical soils. Construct Build Mater 2004;18:2637.

[8] Puppala A, Musenda C. Effects of fiber reinforcement on strength and volume change behavior of two expansive soils. Trans Res Boa 2000;1736:134-40.

[9] Michalowiski L, Zhao A. Failure of fiber-reinforced granular soils. J Geotech Eng ASCE 1996;122:226-34.

[10] Sawicki A. Plastic limit behavior of reinforced earth. J Geotech Eng ASCE 1983;109:1000-5.

[11] Li C. Mechanical response of fiber-reinforced soil, PhD thesis, Faculty of the Graduate School of the University of Texas at Austin; 2005.

[12] Jamshidi R, Towhata I, Ghiassian H, Tabarsa R. Experimental evaluation of dynamic deformation characteristics of sheet pile retaining walls with fiber reinforced backfill. Soil Dyn Earthq Eng 2010;30:438-46.

[13] Ghiassian H, Jamshidi R, Tabarsa A. Dynamic performance of Toyoura sand reinforced with randomly distributed carpet waste strips. In: 4th Dec geol earth eng and soil dyn conf, Sacramento, California, USA; 2008,18-22.

[14] Abtahi M, Ebadi F, Hejazi M, Sheikhzadeh M. On the use of textile fibers to achieve mechanical soil stabilization. In: 4th Int tex cloth des conf, Dubrovnik, Croatia; 5-8 October, 2008.

[15] Wu T, McOmber M, Erb T, Beal E. Study of soil-root interaction. J Geotech Eng ASCE 1988;114:1351-75.

[16] Greenwood J. SLIP4EX - a program for routine slope stability analysis to include the effects of vegetation, reinforcement and hydrological changes. Geotech Geol Eng 2006;24:449-65.

[17] Greenwood J, Norris E, Wint J. Assessing the contribution of vegetation to slope stability. Geotech Eng, Proc the ICE, GE4 2004:199207.

[18] Jewell A, Wroth P. Direct shear tests on reinforced sand. Geotechnique 1987;37:53-68.

[19] Palmeira M, Milligan E. Large scale direct shear tests on reinforced soil. Soil Found 1989;29:18-30.

[20] Al Refeai O. Behaviour of granular soils reinforced with discrete randomly oriented inclusions. Geotext Geomembr 1991;10:319-33.

[21] Consoli C, Prietto M, Ulbrich A. Influence of fiber and cement addition on behavior of sandy soil. J Geotech Eng ASCE 1989;124:1211-4.

[22] Consoli C, Festugato L, Heineck S. Strain-hardening behavior of fiber reinforced sand in view of filament geometry. Geosynth Int 2009;16:109-15.

[23] Abtahi M, Sheikhzadeh M, Hejazi M. Fiber-reinforced asphalt-concrete mixtures - a review. Construct Build Mater 2010;24:871-7.

[24] Baker W. The reinforcement of turf grass areas using plastics and other synthetic materials: a review. Int Turf Grass Soc Res $\mathbf{J}$ 1997;8:3-13. S.M. Hejazi et al. / Construction and Building Materials 30 (2012) 100-116 113

[25] McGown A, Andrawes Z, A1-Hasani M. Effect of inclusion properties on the behavior of sand. Geotechnique 1978;28:327-46.

[26] Kaniraj R, Gayathri V. Geotechnical behavior of fly ash mixed with randomly oriented fiber inclusions. Geotext Geomembr 2003;21:123-49.

[27] Brown B, Sheu S. Effect of deforestation on slopes. J Geotech Eng ASCE 1975;101:147-65.

[28] Waldron J. Shear resistance of root-permeated homogeneous and stratified soil. Soil Sci Soc Am J 1977;41:843-9.

[29] Wu H, Erb T. Study of soil-root interaction. J Geotech Eng ASCE 1988;114:1351-75.

[30] Wu H, Beal E, Lan C. In-situ shear test of soil-root system. J Geotech Eng ASCE 1988;114:1376-94.

[31] Abtahi M, Okhovat N, Hejazi M. Using textile fibers as soil stabilizers - new achievements. In: 1st Int and 7th nat conf text eng, Rasht, Iran; 2009.

[32] Rao J. Jute geotextile for improving the performance of highway embankment on soft marine soil. In: Proc nat sem jute based geotextiles, New Delhi, India; 1996.

[33] Vidal H. The principle of reinforced earth. High Res Rec 1969;282:1-16.

[34] Akbulut S, Arasan S, Kalkan E. Modification of clayey soils using scrap tire rubber and synthetic fibers. App Clay Sci 2007;38:23-32.

[35] Juyol P, Sastry G, Rao M. Rehabilitation of a mined area in Himalaya by Geojute and other measures. In: Proce 5th int conf on geotextiles, Singapore; 1994.

[36] Azeem A, Ati A. Erosion and control techniques for slopes of banks and cuttings. In: Ind geotech conf, Calcutta; 1992.

[37] Leflaive E. Soil reinforced with continuous yarns: Texol. In: 11th Int conf on soil mech and found eng, San Francisco, USA; 1985.

[38] Hanafi I, Few C. Partial replacement of silica by white rice husk ash in natural rubber compounds: the effects of bond. Iran Polym J 1998;7:255-61.

[39] Rowell M, Han S, Rowell S. Characterization and factors effecting fiber properties. Nat Polym Agr Compos 2000:115-34.

[40] Ghavami K, Filho R, Barbosa P. Behaviour of composite soil reinforced with natural fibers. Cement Concrete Compos 1999;21:39-48.

[41] Savastano H, Warden G, Coutts P. Brazilian waste fibers as reinforcement for cement-based composites. Cement Concrete Compos 2000;22: 379-84.

[42] Nilsson H. Reinforcement of concrete with sisal and other vegetable fibers, Swed Counc for Build Res, Document DIY, Stockholm, Sweden; 1975.

[43] Babu S, Vasudevan K. Strength and stiffness response of coir fiber-reinforced tropical soil. J Mater Civil Eng ASCE 2008;20:571-7.

[44] Subaida A, Chandrakaran E, Sankar N. Laboratory performance of unpaved roads reinforced with woven coir. Geotext Geomembr 2009;27:204-10. 
[45] Chauhan S, Mittal S, Mohanty B. Performance evaluation of silty sand subgrade reinforced with fly ash and fiber. Geotext Geomembr 2008;26:429-35.

[46] Ayyar R, Krishnaswamy R, Viswanadham S. Geosynthetics for foundations on a swelling clay. Int work on geotex, Bangalore, India; 1989.

[47] Viswanadham S. Bearing capacity of geosynthetic reinforced foundation on a swelling clay master of technology dissertation. Madras (India): Indian Institute of Technology; 1989.

[48] Ravishankar U, Raghavan S. Coir stabilised lateritic soil for pavements. In: Indian geotech conf, Ahmedabad, India; 2004.

[49] Khedari J, Watsanasathaporn P, Hirunlabh J. Development of fiber-based soil- cement block with low thermal conductivity. Cement Concrete Compos 2005;27:111-6.

[50] Ramesh N, Krishna V, Mamatha V. Compaction and strength behavior of limecoir fiber treated Black Cotton soil. Geomech Eng 2010;2:19-28.

[51] Mishra S, Mohanty K, Drzal T, Misra M, Hinrichsen G. A review on pineapple leaf fibers, sisal fibers and their biocomposites. Macromol Mater Eng 2004;289:955-74.

[52] Kishore J, Rao K. Moisture absorption characteristics of natural fiber composites. J Reinf Plast Compos 1986;5:141-50.

[53] Yetimoglu T, Salbas O. A study on shear strength of sands reinforced with randomly distributed discrete fibers. Geotext Geomembr 2003;21:103-10.

[54] Yetimoglu T, Inanir M, Inanir E. A study on bearing capacity of randomly distributed fiber-reinforced sand fills overlying soft clay. Geotext Geomembr 2005;23:174-83.

[55] Vasudev D. Performance studies on rigid pavement sections built on stabilized sulfate soils. Msc thesis, University of Texas at Arlington; 2007.

[56] Consoli C, Montardo P, Donato M, Prietto M. Effect of material properties on the behavior of sand-cement-fiber composites. Ground Improv 2004;8:77-90.

[57] Maher H, Ho C. Mechanical properties of kaolinite/fiber soil composite. J Geotech Eng 1994;120:1381-93.

[58] Al-Refeai T. Behavior of granular soils reinforced with discrete randomly oriented inclusions. Geotext Geomembr 1991;10:319-33.

[59] Maher H, Ho C. Behavior of fiber-reinforced cemented sand under static and cyclic loads. Geotech Test J 1993;16:330-8

[60] Murray T, Farrar M. Temperature distributions in reinforced soil retaining walls. Geotext Geomembr 1988;7:33-50.

[61] Gray H, Al-Refeai T. Behavior of fabric versus fiber reinforced sand. J Geotech Eng ASCE 1986;112:809-20.

[62] Park S. Effect of fiber reinforcement and distribution on unconfined compressive strength of fiber-reinforced cemented sand. Geotext Geomembr 2009;27:162-6.

[63] Park S, Kim Y, Choi S, Shin E. Unconfined compressive strength of cemented sand reinforced with short fibers. J Korean Soc Civil Eng 2008;28:213-20.

[64] Gray H, Ohashi H. Mechanics of fiber-reinforcement in sand. J Geotech Eng ASCE 1983;109:335-53.

[65] Maher H, Gray H. Static response of sand reinforced with randomly distributed fibers. J Geotech Eng ASCE 1990;116:1661-77.

[66] Michalowski L, Zhao G. Failure of fiber-reinforced granular soils. J Geotech Eng ASCE 1996;122:226-34.

[67] Zornberg G. Discrete framework for limit equilibrium analysis of fiber reinforced soil. Géotechnique 2002;52:593-604.

[68] Consoli C, Montardo P, Prietto M, Pasa S. Engineering behavior of a sand reinforced with plastic waste. J Geotech Geoenviron Eng ASCE 2002;128: 462-72.

[69] Miller J, Rifai S. Fiber reinforcement for waste containment soil liners. J Environ Eng ASCE 2004;130:981-5. S.M. Hejazi et al. / Construction and Building Materials 30 2012, 100-116 115 